\title{
Associação entre aneurismas de aorta abdominal infrarrenal e doença renal policística autossômica dominante: relato de caso
}

\author{
Association between infrarenal abdominal aortic aneurysm and \\ autosomal dominant polycystic kidney disease: a case report
}

\author{
Milton Alves das Neves Junior, Rafael Couto Melo, Adenauer Marinho de Oliveira Goes Junior, \\ Tatiana Rocha Protta, Alexandre Petnys, Edgar Rabboni*
}

\begin{abstract}
Resumo
A doença renal policística dominante é uma das doenças renais hereditárias mais comuns, podendo apresentar manifestações extrarrenais vasculares de importância clínica, como aneurismas intracranianos, aneurismas aórticos e dissecções arteriais. Relatamos o caso de um paciente masculino, com 66 anos de idade, renal crônico não-dialítico por doença renal policística dominante, com aneurisma de aorta abdominal infrarrenal assintomático, diagnosticado por ultrassonografia de rotina e operado eletivamente com sucesso. A doença renal policística dominante é uma síndrome genética, associada aos genes PDK1 e PDK2 no cromossomo 16. A expressão desses genes na parede dos vasos leva ao seu enfraquecimento, favorecendo a formação de aneurismas. A produção de metaloproteinases pelos túbulos renais também estaria relacionada às doenças vasculares desses pacientes. Tais doenças se apresentam como importantes fatores de mortalidade precoce e morbidade dos portadores de doença renal policística dominante e, como usualmente são assintomáticas, justifica-se o uso de propedêutica armada e tratamento precoce.
\end{abstract}

Palavras-chave: Aneurisma aórtico, rim policístico autossômico dominante, insuficiência renal crônica.

\section{Introdução}

A doença renal policística dominante é uma das doenças renais hereditárias mais comuns ${ }^{1}$. É primariamente caracterizada pela formação de múltiplos cistos renais bilateralmente e frequentemente em fígado e pâncreas ${ }^{2}$. Apesar de os cistos renais serem detectados já na infância, a insuficiência renal instala-se entre a terceira e quarta década de vida ${ }^{2}$, devido a substituição de parênquima renal funcionante por múltiplos cistos. É causada por mutações no gene PKD1, levando a doença renal policística dominante tipo I ( $85 \%$ dos casos) ou mutações no gene PKD2

\begin{abstract}
Autosomal dominant polycystic kidney disease (ADPKD) is one of the most common hereditary renal diseases, which may present important clinical extrarenal vascular manifestations, such as intracranial and aortic aneurysms and artery dissections. We report the case of a 66-year-old male chronic renal out-of-dialysis patient, with dominant polycystic kidney disease, presenting an asymptomatic infrarenal abdominal aortic aneurysm diagnosed by routine ultrasonography, submitted to successful elective surgery. ADPKD is a genetic syndrome, associated with PDK1 and PDK2 genes on chromosome 16. The expression of these genes in the vessel walls leads to vessel wall weakening, favoring aneurysm formation. In addition, metalloproteinase production by kidney tubules could be related to vascular diseases in ADPKD patients. These are important factors of early mortality and of morbidity in patients with ADPKD, thus the use of equipped propedeutics and early treatment are indicated, as these manifestations are usually asymptomatic.
\end{abstract}

Keywords: Aortic aneurysm, autosomal dominant polycystic kidney, chronic renal insufficiency.

causando a doença renal policística dominante tipo II $(15 \% \text { dos casos })^{1}$, ambos localizados no cromossomo 16 p33.3. Além disso, a produção e secreção aumentada de metaloproteinases pelos túbulos renais estariam envolvidas com as manifestações da doença ${ }^{3}$.

Várias manifestações extrarrenais são relatadas na literatura. Do ponto de vista vascular, aneurismas de aorta abdominal ${ }^{2}$, periféricos ${ }^{4}$, viscerais ${ }^{4}$, dissecção de aorta torácica $^{5}$ e carótidas ${ }^{6}$ e aneurismas intracranianos ${ }^{7,8}$ são descritos. Tais alterações, se não diagnosticadas e corrigidas, podem ser causa de mortalidade precoce desses pacientes.

\footnotetext{
* Hospital do Servidor Público Municipal, São Paulo, SP.

Não foram declarados conflitos de interesse associados à publicação deste artigo. Artigo submetido em 01.09.08, aceito em 13.01.09.

J Vasc Bras. 2009;8(2):186-188.

Copyright $\odot 2009$ by Sociedade Brasileira de Angiologia e de Cirurgia Vascular
} 


\section{Relato do caso}

Paciente masculino, 66 anos, casado. Faz acompanhamento na nefrologia por insuficiência renal não-dialítica devido à doença renal policística dominante. É hipertenso controlado em uso de nifedipina e furosemida. Apresentava exames laboratoriais normais, exceto por uma dosagem de creatinina sérica de 3,3. Encaminhado ao serviço de cirurgia vascular com achado de aneurisma de aorta abdominal a ultrassonografia de rotina. Clinicamente, apresentava-se assintomático. Apresentava boa perfusão de membros inferiores, com pulsos infrainguinais presentes e cheios. Realizada tomografia computadorizada de abdome sem contraste, que evidenciou múltiplos cistos renais bilaterais além de cistos hepáticos e dilatação aneurismática da aorta abdominal infrarrenal de 4,3 $\mathrm{cm}$ em seu maior diâmetro (Figura 1). Apresentava crescimento de $0,6 \mathrm{~cm}$ em seu maior diâmetro, comparado com a última tomografia realizada há 6 meses. Submetido à correção cirúrgica por acesso transperitoneal, com enxerto aortobiilíaco, com clampeamento infrarrenal e interposição de prótese de dacron $18 \times 9 \mathrm{~mm}$ bifurcada. A presença dos cistos renais e hepático não ofereceu dificuldade no ato cirúrgico e o pós-operatório transcorreu sem intercorrências. Não houve alteração da função renal. Recebeu alta hospitalar no sétimo dia pós-operatório. O paciente mantém seguimento ambulatorial.

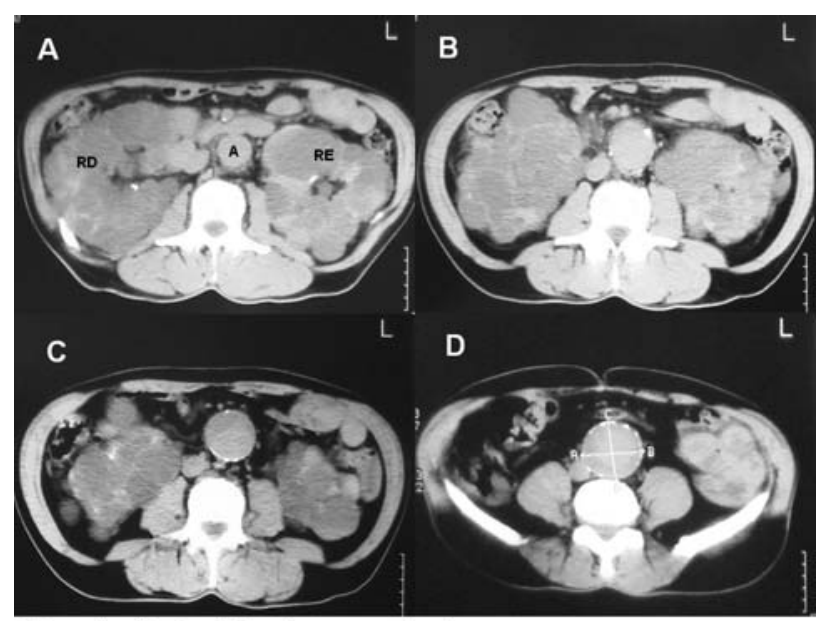

$\mathrm{RD}=\operatorname{rim}$ direito; $\mathrm{RE}=\operatorname{rim}$ esquerdo; $\mathrm{A}=$ aorta.

Figura 1 - Tomografia computadorizada de abdome sem contraste endovenoso evidenciando A) corte na altura da veia renal esquerda, mostrando a presença dos rins policísticos e aorta ainda de tamanho normal; B, C, D) à medida que são feitos cortes inferiores, nota-se o aumento progressivo do diâmetro da aorta até o nível $\mathrm{D}$, onde mede $4,3 \mathrm{~cm}$

\section{Discussão}

A doença renal policística dominante tem prevalência significativa entre os pacientes dialíticos, chegando, em alguns estudos, a 7,6\% dos $\operatorname{casos}^{1}$. As manifestações extrarrenais da doença são responsáveis por alta morbimortalidade desses pacientes.

Cerca de $8 \%$ dos pacientes com doença renal policística dominante apresenta aneurismas intracranianos assintomáticos ${ }^{8}$. A taxa de ruptura é de 1/2.000 pessoas por ano, índice cinco vezes maior que na população em geral ${ }^{8}$, sendo responsável pela mortalidade precoce desses pacientes ${ }^{7}$.

Os aneurismas de aorta abdominal podem ocorrer nos pacientes com doença renal policística dominante ${ }^{2}$. Estudos da literatura mostram incidência variando entre 0,7 e $9,7 \%$ de aneurismas de aorta abdominal em pacientes com doença renal policística dominante ${ }^{2}$. Apesar de sua baixa incidência, os aneurismas de aorta abdominal, quando rotos, apresentam taxa de mortalidade entre 30 e $55 \%$, valor muito maior que nas cirurgias eletivas. Isso justifica a realização de exames complementares em tais pacientes, visando a surpreender aneurismas assintomáticos e corrigi-los eletivamente ${ }^{2}$. Tanto no preparo pré-operatório como na cirurgia, os cuidados com paciente renal crônico devem ser mantidos, tais como o uso de tomografia sem contraste, hidratação adequada, menor tempo de clampeamento aórtico e clampeamento infrarrenal se possível, visto que a presença de insuficiência renal está associada à maior morbimortalidade dos pacientes submetidos a correção cirúrgica dos aneurisma de aorta. Além dos aneurismas, as dissecções de aorta torácica e dos troncos supraaórticos também são descritas na literatura nos pacientes com doença renal policística dominante.

Os tipos I e II da doença estão relacionados aos genes PKD I e PKD II, respectivamente localizados no cromossomo 16. Estes codificam proteínas chamadas policistina do tipo I e II, as quais estão relacionadas à integridade estrutural dos vasos sanguíneos ${ }^{8}$. Estudos de aneurismas em pacientes com doença renal policística dominante mostram a expressão dessas proteínas em sua parede. Além disso, tais pacientes apresentam alterações de componentes da matriz extracelular, tais como fibronectina, colágeno do tipo IV e proteoglicanos ${ }^{5}$. Essas alterações nos pacientes também seriam responsáveis pela fraqueza da parede arterial, ocasionando aneurismas e dissecções. 
As alterações genéticas do cromossomo 16 foram inicialmente descritas em uma família com vários indivíduos apresentando doença renal policística dominante e dilatações vasculares ${ }^{9}$.

A fraqueza da parede dos vasos, associada a hipertensão arterial que esses pacientes apresentam, está relacionada à maior incidência de dissecções arteriais ${ }^{5,6}$. Particularmente nos casos de aneurismas de aorta abdominal em pacientes com doença renal policística dominante, além dos defeitos nos genes PKD1 e PKD2, outra hipótese também é apresentada na patogênese da doença: a secreção aumentada de metaloproteinases pelos túbulos renais desses doentes, especialmente as metaloproteinases 2 e metaloproteinases 9. Takagi \& Umemoto $^{3}$ demonstraram níveis elevados de metaloproteinases na corrente sanguínea e na parede da aorta aneurismática. A metaloproteinase 2 seria responsável pela degradação da elastina na parede da aorta e sua substituição por colágeno, enfraquecendo sua parede e favorecendo o aparecimento de aneurismas ${ }^{10}$. A metaloproteinase 9 tem ação quimiotáxica sobre macrófagos, neutrófilos e outras células inflamatórias, levando a uma inflamação crônica da parede do vaso ${ }^{10}$.

Dessa forma, observamos que as alterações vasculares dos pacientes com doença renal policística dominante fazem parte de uma síndrome genética complexa, que se expressa não só com cistos renais. Dentre as manifestações extrarrenais, as vasculares, na sua maioria assintomática, são responsáveis por uma taxa significativa de morbimortalidade precoce nesses pacientes, justificando a utilização de propedêutica armada em sua investigação e correção eletiva precoce.

\section{Referências}

1. Romão EA, Moysés Neto M, Teixeira SR, Muglia VF, Vieira-Neto OM, Dantas M. Renal and extrarenal manifestations of autosomal dominant polycystic kidney disease. Braz J Med Biol Res. 2006;39:533-8.

2. Torra R, Nicolau C, Badenas C, et al. Abdominal aortic aneurysms and autosomal dominant polycystic kidney disease. J Am Soc Nephrol. 1996;7:2483-6.

3. Takagi H, Umemoto T. Matrix metalloproteinases synthesized in autosomal dominant polycystic kidney disease play a role in development of a concurrent abdominal aortic aneurysm. Med Hypotheses. 2005;64:778-81.

4. Picazo M, Cuxart M, Nadal C, Sans R. Aneurisma de la arteria esplénica y disección arterial femoro-ilíaca en la poliquistosis renal autosómica dominante. Nefrología. 2007;27:223-4.

5. Paynter HE, Parnham A, Feest TG, Dudley CR. Thoracic aortic dissection complicating autosomal dominant polycystic kidney disease. Nephrol Dial Transplant. 1997;12:1711-3.

6. Bobrie G, Brunet-Bourgin F, Alamowitch S, et al. Spontaneous artery dissection: is it part of spectrum of autossomal dominant polycystic kidney disease? Nephrol Dial Transplant. 1998;13:2138-41.

7. Schrier RW, Belz MM, Johnson AM, et al. Repeat imaging for intracranial aneurysms in patients with autosomal dominant polycystic kidney disease with initially negative studies: a prospective ten-year follow-up. J Am Soc Nephrol. 2004; $15: 1023-8$.

8. Pirson Y, Chauveau D, Torres V. Management of cerebral aneurysms in autosomal dominant polycystic kidney disease. J Am Soc Nephrol. 2002;13:269-76.

9. Somlo S, Rutecki G, Giuffra LA, Reeders ST, Cugino A, Whittier FC. A kindred exhibiting cosegregation of an overlap connective tissue disorder and the chromosome 16 linked form of autosomal dominant polycystic kidney disease. J Am Soc Nephrol. 1993;6:1371-8.

10. Hobeika MJ, Thompson RW, Muhs BE, Brooks PC, Gagne PJ. Matrix metalloproteinases in peripheral vascular disease. J Vasc Surg. 2007;45:849-57.

Correspondência:

Milton Alves das Neves Junior

Serviço de Cirurgia Vascular - HSPM

Rua Castro Alves, $60 / 5^{\circ}$ andar, Bairro Aclimação

CEP 01532400 - São Paulo, SP

Tel.: (11) 3208.2211, ramal 223

E-mail: miltonanj@yahoo.com.br 